\title{
Locomotor Stimulant and Rewarding Effects of Inhaling Methamphetamine, MDPV, and Mephedrone via Electronic Cigarette-Type Technology
}

\author{
Jacques D Nguyen', Shawn M Aarde', Maury Cole², Sophia A Vandewater', Yanabel Grant' and \\ Michael A Taffe*,I \\ 'Committee on the Neurobiology of Addictive Disorders, The Scripps Research Institute, La Jolla, CA, USA; ${ }^{2}$ La Jolla Alcohol Research, La Jolla, CA, \\ USA
}

\begin{abstract}
Although inhaled exposure to drugs is a prevalent route of administration for human substance abusers, preclinical models that incorporate inhaled exposure to psychomotor stimulants are not commonly available. Using a novel method that incorporates electronic cigarette-type technology to facilitate inhalation, male Wistar rats were exposed to vaporized methamphetamine (MA), 3,4-methylenedioxypyrovalerone (MDPV), and mephedrone (4-methylmethcathinone) in propylene glycol vehicle using concentrations ranging from 12.5 to $200 \mathrm{mg} / \mathrm{ml}$. Rats exhibited increases in spontaneous locomotor activity, measured by implanted radiotelemetry, following exposure to methamphetamine $(12.5$ and $100 \mathrm{mg} / \mathrm{ml})$, MDPV $(25,50$, and $100 \mathrm{mg} / \mathrm{ml})$, and mephedrone $(200 \mathrm{mg} / \mathrm{ml})$. Locomotor effects were

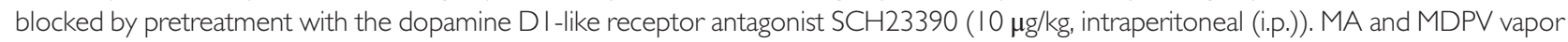
inhalation also altered activity on a running wheel in a biphasic manner. An additional group of rats was trained on a discrete trial intracranial self-stimulation (ICSS) procedure interpreted to assess brain reward status. ICSS-trained rats that received vaporized MA, MDPV, or mephedrone exhibited a significant reduction in threshold of ICSS reward compared with vehicle. The effect of vapor inhalation of the stimulants was found comparable to the locomotor and ICSS threshold-reducing effects of i.p. injection of mephedrone (5.0 mg/kg), MA (0.5-1.0 mg/kg), or MDPV (0.5-1.0 mg/kg). These data provide robust validation of e-cigarette-type technology as a model for inhaled delivery of vaporized psychostimulants. Finally, these studies demonstrate the potential for human use of e-cigarettes to facilitate covert use of a range of psychoactive stimulants. Thus, these devices pose health risks beyond their intended application for the delivery of nicotine. Neuropsychopharmacology (2016) 4I, 2759-277I; doi:I0.I038/npp.2016.88; published online 29 June 2016
\end{abstract}

\section{INTRODUCTION}

The inhalation of psychomotor stimulant drugs is a major route of administration and this may be associated with enhanced dependence liability. Inhaled use of methamphetamine is more common than other routes of administration in habitual and dependent users (Das-Douglas et al, 2008; Heinzerling et al, 2010; Wood et al, 2008). Furthermore, the SAMHSA/TEDS treatment admission database for 2012 shows $4.7 \%$ of treatment seekers in the United States were admitted for smoked cocaine vs 2.2\% for other routes of cocaine administration as the primary reason for treatment (http://wwwdasis.samhsa.gov/webt/new mapv1.htm). The recent availability of e-cigarette technology has further facilitated inhalation of methamphetamine (Evans, 2014; Rass et al, 2015), 'bath salts' (Johnson and Johnson, 2014; Rass et al, 2015), and 'flakka' (presumptively

*Correspondence: Dr MA Taffe, Committee on the Neurobiology of Addictive Disorders, The Scripps Research Institute, SP30-2400, 10550 North Torrey Pines Road, La Jolla, CA 92037, USA, Tel: + I 858784 7228, Fax: + I 858784 7405, E-mail: mtaffe@scripps.edu

Received 19 April 2016; revised 2 June 2016; accepted 3 June 2016; accepted article preview online 9 June 2016 $\alpha$-pyrrolidinopentiophenone $(\alpha$-PVP) $) \quad$ as reported (Anderson, 2015) in one case of paranoid public behavior. Additional evidence exists in popular drug-user forums, such as www.bluelight.org, which host subthreads for the discussion of administering several different stimulants in e-cigarettes. Thus, better laboratory models of inhaled stimulant exposure are needed. Monkeys can be trained to smoke cocaine base (Comer et al, 1994, 1995) or methamphetamine (Newman and Carroll, 2006) and rats and mice have been exposed involuntarily to cocaine or methamphetamine in a restraint preparation (Lichtman et al, 1995; Meng et al, 1999). Apart from one recently described model for crack cocaine (Hueza et al, 2016), preclinical models of inhaled exposure to stimulants in unrestrained are not generally available.

This study was conducted to validate a method for the delivery of stimulants to unrestrained rats via inhalation. Housing chambers were modified to deliver stimulant drugs in propylene glycol vapor to rats under controlled ventilation conditions. It was hypothesized that inhalation of methamphetamine (MA) and the substituted cathinones 3,4-methylenedioxypyrovalerone (MDPV) and mephedrone (4-methylmethcathinone (4MMC)) would increase spontaneous locomotor activity and alter body temperature as 
measured in unrestrained rats with an implanted radiotelemetry devices. The behavioral measures were selected for validation purposes because earlier attempts to deliver MA to rats using a different inhalation method (see George et al, 2010 for the approach that was used) produced detectable blood levels of MA without any clear evidence of a behavioral or thermoregulatory effect. These drugs were selected because they span the range from traditional stimulant (MA) to entactogen (mephedrone) to restricted transporter inhibitor (MDPV) and thus the results would generalize across these subclasses (Simmler et al, 2013). Administration of each of these drugs by injection has been shown to increase activity of rats as measured by radiotelemetry (Aarde et al, 2013b; Miller et al, 2013a; Wright et al, 2012), beam break (Baumann et al, 2012, 2013), or an activity wheel (Huang et al, 2012) in prior experiments, and therefore locomotor assessment is a valid approach for detecting in vivo effects of inhalation. Further experiments were conducted to determine whether intracranial self-stimulation (ICSS) reward thresholds are reduced by vapor exposure to stimulants, as has been reported following intraperitoneal (i.p.) administration of MA (Bauer et al, 2013), MDPV (Bonano et al, 2014), or mephedrone (Robinson et al, 2012). Finally, the effects of i.p. injection of MA, MDPV, or mephedrone on locomotor behavior, body temperature, and ICSS thresholds were determined to compare with the magnitude of effects produced by inhalation.

\section{MATERIALS AND METHODS}

\section{Subjects}

Male Wistar (Charles River, New York, NY) rats $(N=21$ for radiotelemetry; $N=12$ for ICSS reward; $N=23$ for wheel activity) were housed in humidity- and temperaturecontrolled $\left(23 \pm 1^{\circ} \mathrm{C}\right)$ vivaria on $12: 12 \mathrm{~h}$ light/dark cycles. Animals entered the laboratory at 10 weeks of age and were 14 weeks old and weighed 291-322 g at the start of this study. Animals had ad libitum access to food and water in their home cages. All procedures were conducted under protocols approved by the institutional care and use committees of The Scripps Research Institute and in a manner consistent with the Guide for the Care and Use of Laboratory Animals (National Research Council (US) Committee for the Update of the Guide for the Care and Use of Laboratory Animals; Institute for Laboratory Animal Research (US), 2011).

\section{Drugs}

D-methamphetamine $\mathrm{HCl}$ (MA; NIDA Drug Supply), 3,4-methylenedioxypyrovalerone $\mathrm{HCl}$ (MDPV; Fox Chase Chemical Diversity Center, Doylestown, PA), and 4-methylmethcathinone $\mathrm{HCl}$ (mephedrone; synthesized as previously described in Miller et al, 2013a, Supplementary Materials) were delivered in propylene glycol (PG) vehicle (at concentrations of $12.5-200 \mathrm{mg} / \mathrm{ml}$ ) using e-cigarette-type cartridges for vapor inhalation sessions. The chamber air is vacuum controlled by a chamber exhaust valve (ie, a 'pull' system) to flow room ambient air through an intake valve at 11 per min. This also functions to ensure that vapor enters the chamber on each device triggering event. The vapor stream is integrated with the ambient air stream once triggered. Four 10-s vapor puffs were delivered with 2-s intervals every $5 \mathrm{~min}$, resulting in use of $\sim 0.125 \mathrm{ml}$ per $40 \mathrm{~min}$ exposure session. The vacuum was turned off for the $4 \mathrm{~m}, 12 \mathrm{~s}$ interval between deliveries. Drugs for the i.p. route of administration were dissolved in physiological saline (MA: 0.5, $1.0 \mathrm{mg} / \mathrm{kg}$ i.p.; MDPV: 0.5, $1.0 \mathrm{mg} / \mathrm{kg}$ i.p.; mephedrone: 1.0, $5.0 \mathrm{mg} / \mathrm{kg}$ i.p.; SCH23390: 3.0, 10.0 нg/kg, i.p.). SCH23390 $\mathrm{HCl}$ was obtained from Cayman Chemical. Dosing is expressed as the salt in all cases.

\section{Apparatus}

Sealed exposure chambers were modified from the $259 \mathrm{~mm} \times 234 \mathrm{~mm} \times 209 \mathrm{~mm}$ Allentown rat cage to regulate airflow and the delivery of vaporized drug to rats using e-cigarette devices (Figure 1a). The latter included the Protank 3 Atomizer by Kanger Tech (Shenzhen Kanger Technology, Fuyong Town, Shenzhen, China) and the 510 DCT Tank Atomizer by Ego E-Cigs (Joyetech USA, Irvine, CA). A custom interface has been developed to permit triggering of the device by MedPC IV software (Med Associates, St Albans, VT) and integration of the vapor stream into the chamber air inflow.

\section{Radiotransmitter Implantation}

Rats were anesthetized with an isoflurane/oxygen vapor mixture (isoflurane 5\% induction, 1-3\% maintenance), and sterile radiotelemetry transmitters (Data Sciences International; TA-F40) were implanted in the abdominal cavity through an incision along the abdominal midline posterior to the xyphoid space as previously reported (Aarde et al, 2015b; Miller et al, 2013a; Wright et al, 2012). Absorbable sutures were used to close the abdominal muscle incision and the skin incision was closed with the tissue adhesive (3M Vetbond Tissue Adhesive; 3M, St Paul, MN). A minimum of 7 days was allowed for surgical recovery before starting experiments. For the first 3 days of the recovery period, an antibiotic Cefazolin (Hikma Farmaceutica, Portugal; $0.4 \mathrm{mg} / \mathrm{kg}$, i.m. in sterile water day 1 , s.c. days 2-3) and an analgesic flunixin (FlunixiJect, Bimeda USA, Oakbrook Terrace, IL; $2.5 \mathrm{mg} / \mathrm{kg}$, s.c. in saline) were administered daily.

\section{Radiotelemetry Measures of Locomotor Activity and Body Temperature}

Locomotor activity and temperature data were collected while animals were housed in clean standard plastic homecages (thin layer of bedding) in a dark testing room (dim red-light illumination), separate from the vivarium, during the (vivarium) dark cycle. Radiotelemetry transmissions were collected via receiver plates (Data Sciences International; RPC-1) placed under the cages as described in prior investigations (Aarde et al, 2013b; Miller et al, 2013a; Taffe et al, 2015a; Wright et al, 2012). The ambient temperature for the studies was $20 \pm 1{ }^{\circ} \mathrm{C}$.

Sessions started with a 30 -min interval in the recording cage to determine a pretreatment baseline of activity and temperature. Thereafter, animals were placed in the inhalation chamber, in pairs, for the vapor exposure (40 min) and then returned to their individual recording cages. The i.p. injection sessions were conducted similarly with the drug 
a

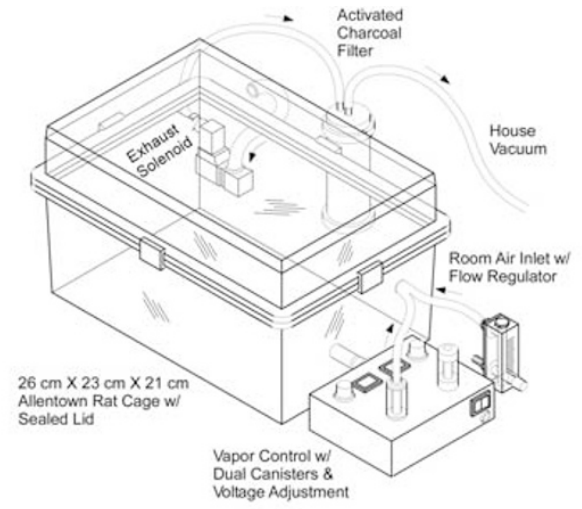

b

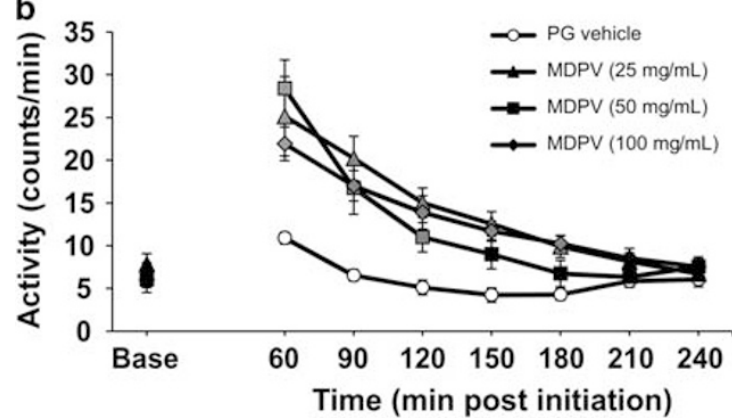

C
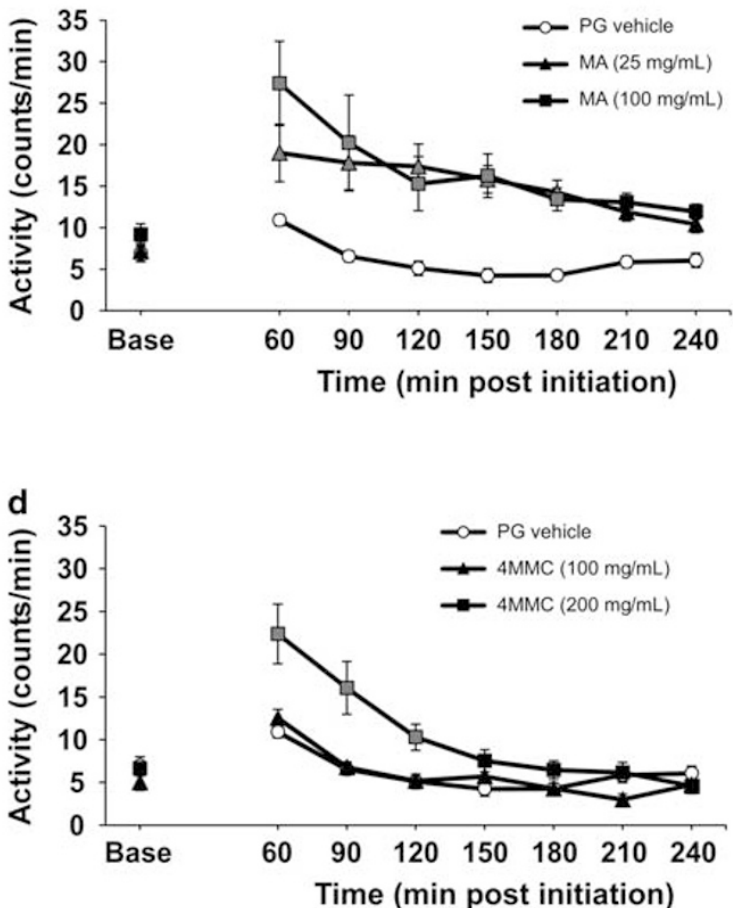

Figure I (a) Schematic of the apparatus. Mean ( $\mathrm{N}=13$; +SEM) activity rates after inhalation of (b) methamphetamine (MA; 25,I00 mg/ml), (c) 3,4-methylenedioxypyrovalerone (MDPV; 25, 50, $100 \mathrm{mg} / \mathrm{ml}$ ), and (d) 4-methylmethcathinone (4MMC/mephedrone; $100,200 \mathrm{mg} / \mathrm{ml}$ ). Gray shaded symbols indicate a significant difference from PG vehicle at the corresponding time point. Base $=$ preinhalation baseline.

administered just before placement in the inhalation chamber (that flowed clean air only throughout these sessions) in pairs. The three telemetry samples taken before moving the rat to the inhalation chamber were used as the pretreatment baseline. Primary analysis focused on the average activity rate and body temperature in $30 \mathrm{~min}$ intervals as derived from the primary $5 \mathrm{~min}$ sampling bins. Data are timed to the initiation of the vapor session, and thus the ' 60 min' time bin reflects the average of 3-4 samples collected after return to the recording chamber following the 40 min vapor exposure. All subsequent time bins reflect the average of six 5-min samples. Any missing body temperature data (eg, because of radio interference or animal's location within the chamber at the time of sampling) was interpolated across preceding and succeeding recorded values.

\section{Experiment 1}

Rats (group $1 ; N=13 ; 14$ weeks of age and a mean of $497.5 \mathrm{~g}$ at the start of the study) were initially exposed to a habituation condition, and then MA (100 mg/ml). Thereafter, PG, MA (25 mg/ml), MDPV $(25,50,100 \mathrm{mg} / \mathrm{ml})$, and mephedrone $(100,200 \mathrm{mg} / \mathrm{ml})$ were administered on separate session in a mixed order with no less than 3-4 days between active doses. In addition to the inhalation sessions for PG, MA, MDPV, and mephedrone as reported, animals received additional vapor inhalation sessions of methylone $(100 \mathrm{mg} / \mathrm{ml})$, cocaine $(200 \mathrm{mg} / \mathrm{ml}), \alpha$-PVP $(25,100 \mathrm{mg} / \mathrm{ml}$; 20 and $40 \mathrm{~min}$ sessions), and additional MDPV sessions $(100 \mathrm{mg} / \mathrm{ml}$; $1-2$ vapor puffs per $5 \mathrm{~min}$; durations of 5-20 $\mathrm{min}$ ) before the doses reported in experiment 2 .

\section{Experiment 2}

This experiment consisted of a repetition of the PG, MA $(100 \mathrm{mg} / \mathrm{ml})$, and MDPV $(100 \mathrm{mg} / \mathrm{ml})$ inhalation conditions in a balanced order, followed by i.p. administration (MA: 0.5, $1.0 \mathrm{mg} / \mathrm{kg}$ i.p.; MDPV: $0.5,1.0 \mathrm{mg} / \mathrm{kg}$ i.p.; mephedrone: 1.0 , $5.0 \mathrm{mg} / \mathrm{kg}$ i.p.) in a balanced order with no less than 3-4 days between active doses. The i.p. studies were conducted several months after the original start of vapor inhalation sessions, and thus the inhalation conditions were repeated to determine potential plasticity (tolerance or sensitization) of the stimulant effect and to enhance the route of administration comparison.

\section{Experiment 3}

A new group of rats (group 2; $N=7$; one animal was lost to unknown reasons after an initial MA inhalation session; 14 weeks of age and a mean of $392.6 \mathrm{~g}$ at the start of the experiment) was exposed to one $\mathrm{PG}$ inhalation session for habituation and then in randomized order to vapor inhalation of PG or MA (100 mg/ml in PG) for $40 \mathrm{~min}$ with the administration of $\mathrm{SCH} 23390(0.0,3.0$, and $10 \mu \mathrm{g} / \mathrm{kg}$, i.p.) immediately before the start of vapor inhalation. This served as an initial study to identify an efficacious SCH23390 dose and to refine stimulant exposures for this group (activity was suppressed below vehicle by $40 \mathrm{~min}$ of MA vapor in two subjects, suggesting high-dose stereotypy). Animals were next exposed to $30 \mathrm{~min}$ of PG, MDPV, or mephedrone with pretreatment with vehicle or SCH23390 $(10 \mu \mathrm{g} / \mathrm{kg}$, i.p.) in randomized order and then $30 \mathrm{~min}$ of $\mathrm{MA}$, again with 
pretreatment with vehicle or SCH23390 $(10 \mu \mathrm{g} / \mathrm{kg}$, i.p.). This group was thereafter exposed to 10,20 , or $30 \mathrm{~min}$ of $\mathrm{MA}$ vapor $(12.5 \mathrm{mg} / \mathrm{ml})$ and then MDPV $(12.5 \mathrm{mg} / \mathrm{ml})$ vapor with the order again randomized in pairs within drug identity. This lower concentration was used to probe the lower threshold based on the findings for $25 \mathrm{mg} / \mathrm{ml}$ in experiment 1. As in the other experiments, all rats experienced no less than 3-4 days between active doses.

\section{Experiment 4 Activity Wheel}

For these studies, one cohort $(N=7$; age 14 weeks of age and a mean of $407.1 \mathrm{~g}$ at start of vapor studies) of otherwise naive male Wistar rats was given $2 \mathrm{~h}$ access to the wheel following $40 \mathrm{~min}$ of exposure to first PG, MA $(25 \mathrm{mg} / \mathrm{ml})$, or MDPV $(25 \mathrm{mg} / \mathrm{ml})$ in randomized order and then $40 \mathrm{~min}$ of exposure to PG, MA $(100 \mathrm{mg} / \mathrm{ml})$, or MDPV $(100 \mathrm{mg} / \mathrm{ml})$ in randomized order. The latter condition was repeated twice (with and without $30 \mathrm{~min}$ of wheel habituation that produced no effect), and thus each dose was double determined and the average was used for analysis. A second cohort of male Wistar rats $(N=16$; age 17 weeks of age and a mean of $477.4 \mathrm{~g}$ at start of vapor studies) were given access to an activity wheel (MED Associates; ENV-046) for $2 \mathrm{~h}$ after $20 \mathrm{~min}$ of exposure to $\mathrm{PG}$ or MA vapor $(100 \mathrm{mg} / \mathrm{ml})$ in pairs in a balanced order. Animals had been immunized with KLH three times (weeks 11, 13, and 16 of age) with SAS adjuvant (see Miller et al, 2013b for details) and half had received 90 min of wheel access after each immunization. There were no less than 3-4 days between active doses for all rats in this experiment.

\section{Experiment 5 ICSS}

For these studies, the cohort of rats $(N=12)$ were anesthetized and prepared with unilateral electrodes aimed at the medial forebrain bundle (coordinates: AP $-0.5 \mathrm{~mm}$, $\mathrm{ML} \pm 1.7 \mathrm{~mm}$, DV skull $-9.5 \mathrm{~mm}$ ). Animals were trained in a procedure adapted from the discrete-trial current-threshold procedure (Kenny and Markou, 2006; Kornetsky and Esposito, 1979; Markou and Koob, 1992). Trials begin with a noncontingent stimulation (sinusoidal electrical stimuli of $250 \mathrm{~ms}$ duration and $60 \mathrm{~Hz}$ ), followed by a variable poststimulation interval $(7.5 \mathrm{~s})$ during which delivery of a second stimulus was contingent upon responding with a one-fourth turn of a wheel manipulandum. Each electrical stimulation (reinforcer) had a train duration of $500 \mathrm{~ms}$ during which $0.1 \mathrm{~ms}$ cathodal pulses were delivered at $50-100 \mathrm{~Hz}$, with current-intensity thresholds within $50-200 \mu \mathrm{A}$. Current was varied in a series of steps $( \pm 5 \mu \mathrm{A}$ per step, 3 trials per step). In each testing session, four alternating descending-ascending series were presented. The threshold for each series was defined as the midpoint between two consecutive current intensities that yielded 'positive scores' (animals responded for at least two of the three trials) and two consecutive current intensities that yielded 'negative scores' (animals did not respond for two or more of the three trials). The overall threshold of the session was defined as the mean of the thresholds for the four individual series. Each testing session was $\sim 30 \mathrm{~min}$ in duration. Rats were trained once daily until stable reward threshold were established ( $\leqslant 10 \%$ variation in thresholds for three consecutive days) between 7 and 10 days.

The vapor exposure procedure was the same as described above for the experiment 1 telemetry studies and included PG, MA (100 mg/ml), MDPV (100 mg/ml), and mephedrone $(200 \mathrm{mg} / \mathrm{ml})$. Animals were exposed in pairs, there were no less than 3-4 days between active doses, and each condition was repeated twice for each animal with the drug order counterbalanced across the group within the two sequential dose-response series blocks. For the i.p. challenges, injections were administered $15 \mathrm{~min}$ before the start of the ICSS session. Active drug days were separated by at least one nondrug (or vehicle) session. Thresholds established during drug challenges were represented as a percent of the preceding nondrug baseline session for each individual for analysis. Subjects experienced a 4-week study (not shown here) before this one involving overnight access to activity wheels in the home cage on four sequential days of a week, repeated twice, similar to a study design previously described for drug self-administration (Aarde et al, 2015c). One animal was killed because of loss of electrode cap integrity before these studies. The remaining experimental group $(N=11)$ had no drug exposure before the start of these experiments. One animal exhibited convulsions and died during its second inhalation session during which the PG vehicle was being administered (the first session for this animal was a MA inhalation session) for unknown reasons, and thus $N=10$ for the data reported. One rat failed to complete the task on the second repetition of the MA vapor condition, and thus this individual is omitted from the inhalation data set, but is included in the i.p. dosing.

\section{Data Analysis}

Measures of locomotor activity, body temperature $\left({ }^{\circ} \mathrm{C}\right)$, wheel activity (quarter rotations), and ICSS reward threshold (\% of baseline) were analyzed by repeated-measures analysis of variance (rmANOVA) with Time Bin, Drug Treatment Condition, and/or Route of Administration as withinsubjects factors. The analysis of Route for ICSS was between-subjects because of the failure of one animal to complete the vapor condition. Significant main effects from rmANOVA were further analyzed with post hoc multiple comparisons analysis using Tukey (multi-level factors), Sidak (two-level factors), or Dunnett ( $v s$ vehicle) procedures to correct for multiple comparisons as noted. The criterion for significant results was set at $P<0.05$ and all analyses were conducted using Prism 6 for Windows (v. 6.02; GraphPad Software, San Diego CA).

\section{RESULTS}

\section{Experiment 1: Effect of Inhaled Stimulant Administration on Activity and Body Temperature}

Activity. The inhalation of MA significantly increased locomotor activity in the 25 and $100 \mathrm{mg} / \mathrm{ml}$ concentration test conditions (Figure 1b). The ANOVA confirmed a significant effect of Time $(\mathrm{F}(7,84)=6.93 ; P<0.0001)$ and Drug $(\mathrm{F}(2,24)=19.03 ; P<0.0001)$ and of the Time $\times$ Drug interaction $(\mathrm{F}(14,168)=2.54 ; P<0.005)$. Tukey's post hoc analysis confirmed that locomotor activity was increased 
Table I Body Temperature Responses to Inhaled Stimulants

\begin{tabular}{|c|c|c|c|c|c|c|c|c|}
\hline Base & $38.2( \pm 0.1)$ & $38.0( \pm 0.2)$ & $38.3( \pm 0.1)$ & $38.1( \pm 0.2)$ & $37.7( \pm 0.1)$ & $38.0( \pm 0.2)$ & $37.8( \pm 0.1)$ & $37.9( \pm 0.2)$ \\
\hline $90 \mathrm{~min}$ & $38.2( \pm 0.1)$ & $38.4( \pm 0.1)$ & $38.6( \pm 0.2)$ & $38.4( \pm 0.1)$ & $38.6 *( \pm 0.1)$ & $38.5( \pm 0.1)$ & $38.4( \pm 0.1)$ & $38.3( \pm 0.2)$ \\
\hline $120 \mathrm{~min}$ & $38.0( \pm 0.1)$ & $38.3( \pm 0.1)$ & $38.2( \pm 0.2)$ & $38.2( \pm 0.2)$ & $38.4^{*}( \pm 0.1)$ & $38.5 *( \pm 0.1)$ & $38.1( \pm 0.1)$ & $38.2( \pm 0.2)$ \\
\hline $210 \mathrm{~min}$ & $37.9( \pm 0.1)$ & $38.3 *( \pm 0.1)$ & $38.4^{*}( \pm 0.1)$ & $38.3 *( \pm 0.1)$ & $38.1( \pm 0.1)$ & $38.3 *( \pm 0.2)$ & $37.7( \pm 0.1)$ & $38.0( \pm 0.1)$ \\
\hline $240 \mathrm{~min}$ & $38.1( \pm 0.1)$ & $38.3( \pm 0.1)$ & $38.5^{*}( \pm 0.1)$ & $38.2( \pm 0.1)$ & $38.1( \pm 0.1)$ & $38.4( \pm 0.1)$ & $37.8( \pm 0.1)$ & $38.0( \pm 0.1)$ \\
\hline
\end{tabular}

Abbreviations: MA, methamphetamine; MDPV, 3,4-methylenedioxypyrovalerone; 4MMC, 4-methylmethcathinone; PG, propylene glycol vehicle.

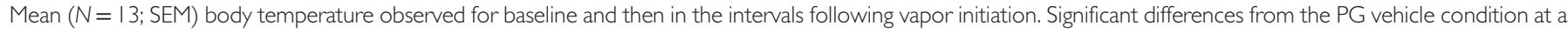
given time point are indicated by the symbol '*' and are in bold.

over the vehicle PG condition after the start of vapor when the $25 \mathrm{mg} / \mathrm{ml}$ (90-180 min after vapor initiation) or $100 \mathrm{mg} / \mathrm{ml} \mathrm{MA}$ (60-150 min after vapor initiation) concentrations were used. Activity did not differ significantly between 100 and $25 \mathrm{mg} / \mathrm{ml}$ concentrations at any time point.

The three different MDPV concentrations similarly increased activity compared with the effect of PG inhalation (Figure 1c). The ANOVA confirmed a significant effect of Time $(F(7,84)=$ 50.83; $P<0.0001)$ and Drug $(\mathrm{F}(3,36)=10.61 ; P<0.0001)$ and of the Time $\times$ Drug interaction $(\mathrm{F}(21,252)=3.84 ; P<0.0001)$. Tukey's post hoc analysis confirmed increased activity relative to PG condition for the $25 \mathrm{mg} / \mathrm{ml}$ (60-180 min after vapor initiation), $50 \mathrm{mg} / \mathrm{ml}(60-120 \mathrm{~min}$ after vapor initiation), and $100 \mathrm{mg} / \mathrm{ml}$ (60-180 $\mathrm{min}$ after vapor initiation) MDPV concentrations. Activity was significantly higher in the $60 \mathrm{~min}$ time point following $50 \mathrm{mg} / \mathrm{ml} \mathrm{MDPV} \mathrm{compared}$ with the $100 \mathrm{mg} / \mathrm{ml}$ MDPV condition.

As shown in Figure 1d, mephedrone (4MMC) increased motor activity at the $200 \mathrm{mg} / \mathrm{ml}$ but not the $100 \mathrm{mg} / \mathrm{ml}$ concentration. The ANOVA confirmed a significant effect of Time $(\mathrm{F}(8,84)=46.02 ; P<0.0001)$ and Drug $(\mathrm{F}(2,24)=8.54$; $P<0.005)$ and of the Time $\times$ Drug interaction $(F(14,168)=5.84$; $P<0.0001)$. Tukey's post hoc analysis confirmed that $200 \mathrm{mg} / \mathrm{ml}$ mephedrone increased motor activity from 60 to $120 \mathrm{~min}$ following exposure compared with either the PG or $100 \mathrm{mg} / \mathrm{ml}$ mephedrone condition.

Temperature. Vapor exposure to MA increased body temperature (Table 1), as confirmed by main effects of Vaporized Dose $\quad(F(2,24)=6.83 ; \quad P<0.005)$, Time $\quad(F(7,84)=20.06$; $P<0.0001)$, and the interaction $(\mathrm{F}(14,168)=2.98 ; P<0.0005)$. Tukey's post hoc test confirmed temperature as being significantly elevated compared with the PG exposure for both the MA $25 \mathrm{mg} / \mathrm{ml}$ (150-210 min after vapor initiation) and MA $100 \mathrm{mg} / \mathrm{ml}(60,210-240 \mathrm{~min}$ after vapor initiation) concentrations.

Vapor exposure to MDPV also increased body temperature (Table 1), as confirmed by main effects of Vaporized Dose $(\mathrm{F}(3,36)=7.77 ; \quad P<0.0005)$, Time $(\mathrm{F}(7,84)=27.70$; $P<0.0001)$, and the interaction $(\mathrm{F}(21,252)=3.73$; $P<0.0001)$. Tukey's post hoc test confirmed temperature as being significantly elevated compared with the PG exposure for $25 \mathrm{mg} / \mathrm{ml}$ MDPV (60, 150-210 min after vapor initiation), $50 \mathrm{mg} / \mathrm{ml} \mathrm{MDPV} \mathrm{(60-120} \mathrm{min} \mathrm{after} \mathrm{vapor} \mathrm{initia-}$ tion), and $100 \mathrm{mg} / \mathrm{ml} \mathrm{MDPV}(60,120-210 \mathrm{~min}$ after vapor initiation).

Vapor exposure to mephedrone did not change body temperature (Table 1). Although the ANOVA confirmed main effects of Time $(F(7,84)=23.04 ; P<0.0001)$ and the interaction of Time with Vaporized Dose $(\mathrm{F}(14,168)=2.41$; $P<0.005)$, Tukey's post hoc test only confirmed temperature as being significantly different from the PG condition at baseline for either mephedrone concentration.

\section{Experiment 2: Effect of Intraperitoneal Stimulant Administration on Activity and Body Temperature}

A follow-up study conducted to assess activity after a second round of PG, MA (100 mg/ml), or MDPV (100 mg/ml) vapor inhalation found that the activity response of the group was slightly attenuated from first (experiment 1, Figures 1a and b) to final drug challenges (experiment 2, Figure 2d). The first analysis compared the effects of $40 \mathrm{~min}$ exposure to MA $(100 \mathrm{mg} / \mathrm{ml}, 4$ puffs every $5 \mathrm{~min})$ and PG across the two determinations and the ANOVA confirmed a significant effect of Time $(\mathrm{F}(7,84)=17.02 ; P<0.0001)$ and Vaporized Drug Condition $(\mathrm{F}(3,36)=15.38 ; P<0.0001)$ and of the Time $\times$ Vaporized Drug Condition interaction $(\mathrm{F}(21,252)=2.45 ; \quad P<0.001)$. Tukey's post hoc analysis confirmed a significant difference between $M A$ and $P G$ vehicle from 60-240 min for the first run (experiment 1), and from 60-120 for the second run (experiment 2). Activity was significantly different between the first and second MA sessions for the $60 \mathrm{~min}$ time bin only and did not differ between the first and second PG sessions for any time bin.

Inhalation of MDPV also significantly increased locomotor activity in both the first (experiment 1) and second (experiment 2) tests. The ANOVA confirmed a significant effect of Time $(F(7,84)=52.48 ; P<0.0001)$ and Vaporized Drug Condition $(\mathrm{F}(3,36)=30.29 ; P<0.0001)$ and of the Time $\times$ Vaporized Drug Condition interaction $(\mathrm{F}(21,252)=5.588$; $P<0.0001$ ). The post hoc analysis (Tukey) confirmed a significant difference between MDPV and PG vehicle from 60-180 min for the first run and $60 \mathrm{~min}$ after vapor initiation for the second run. Activity was significantly different between the first and second MDPV sessions for the 60-150 min time bins 

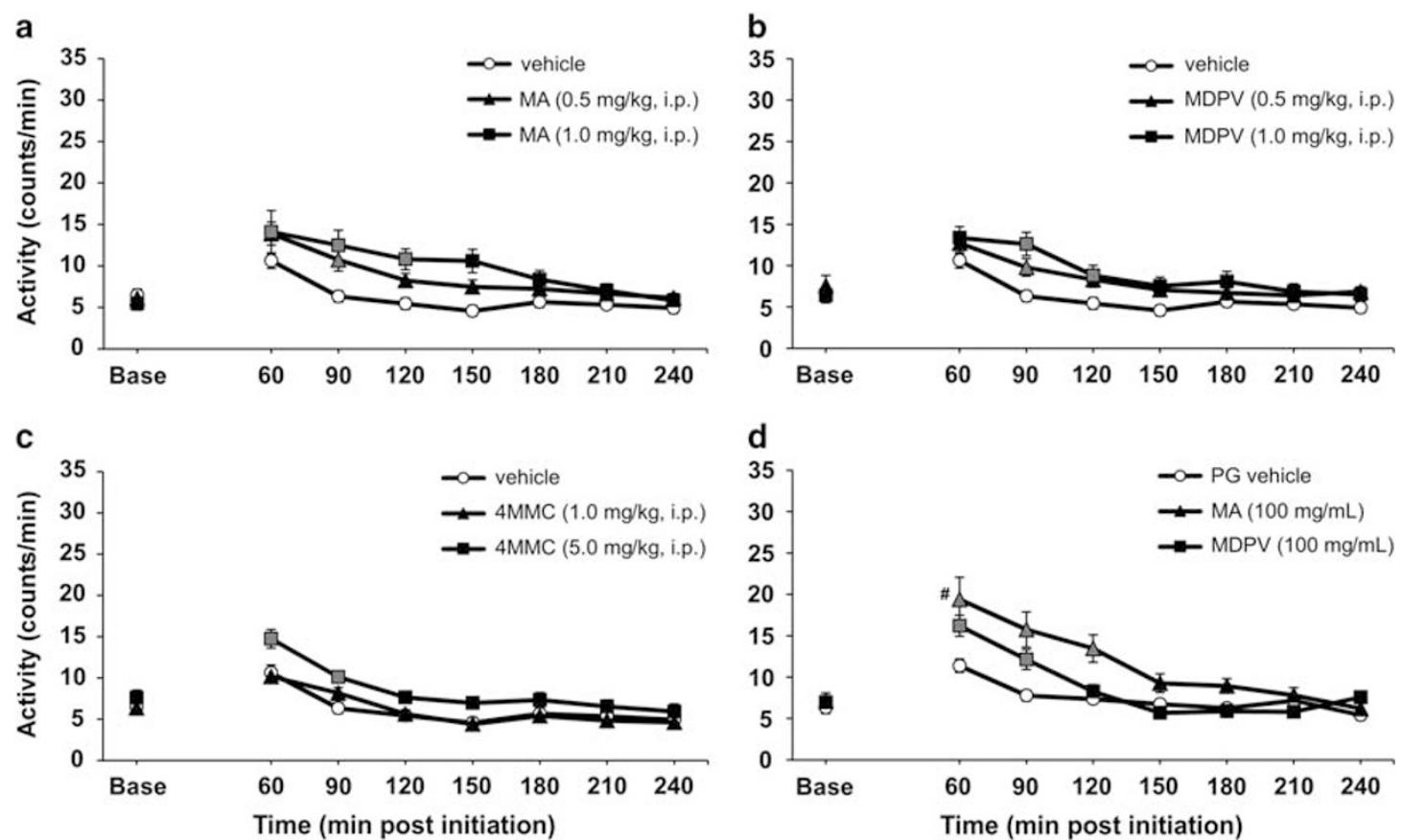

Figure 2 Mean $(N=13$; +SEM) activity rates after intraperitoneal (i.p.) injection of a single vehicle condition compared with doses of (a) MA (0.5, $1.0 \mathrm{mg} / \mathrm{kg})$, (b) MDPV (0.5, $1.0 \mathrm{mg} / \mathrm{kg})$, and (c) $4 \mathrm{MMC}(1.0,5.0 \mathrm{mg} / \mathrm{kg})$. Activity rates after inhalation exposure to the PG vehicle, MA $(100 \mathrm{mg} / \mathrm{ml})$, or MDPV $(100 \mathrm{mg} / \mathrm{ml})$ for the same group are presented in (d). Gray shaded symbols indicate a significant difference from vehicle at the corresponding time point and the symbol \# indicates a significant difference between routes of administration of a given drug at a given time point. Base $=$ preinhalation baseline.

but, again, did not differ between the first and second PG sessions for any time bin.

The i.p. administration of MA, MDPV, and mephedrone increased locomotor activity (Figures $2 \mathrm{a}-\mathrm{c}$ ) and the ANOVA for all i.p. conditions confirmed that there were significant effects of Time after injection $(\mathrm{F}(7,84)=34.59 ; P<0.0001)$ and drug i.p. Dose Condition $(\mathrm{F}(6,72)=6.89 ; P<0.0001)$ and of the interaction of Time and i.p. Dose Condition $(\mathrm{F}(42,504)=1.62 ; P<0.05)$. Tukey's post hoc test confirmed that activity rates were significantly higher following $0.5 \mathrm{mg} / \mathrm{kg}$ (90 min after injection) and $1.0 \mathrm{mg} / \mathrm{kg}(60-120 \mathrm{~min}$ after injection) MA doses, following $0.5 \mathrm{mg} / \mathrm{kg}$ (90 min after injection) and $1.0 \mathrm{mg} / \mathrm{kg}$ (90-120 min after injection) MDPV doses, as well as after the $5.0 \mathrm{mg} / \mathrm{kg}(60-90 \mathrm{~min}$ after injection) mephedrone dose as compared with the vehicle injection.

The i.p. administration of the three drugs also altered body temperature (Table 2); the ANOVA confirmed main effects of Time $(F(7,84)=15.24 ; P<0.0001)$ and i.p. Drug Condition $(\mathrm{F}(6,72)=3.40 ; \quad P<0.01)$ and of the Time $\times$ i.p. Drug Condition interaction $(\mathrm{F}(42,504)=1.64 ; P<0.01)$. Dunnett's post hoc test confirmed significant elevations of body temperature relative to vehicle for $0.5 \mathrm{mg} / \mathrm{kg}$ MA (120-150 min after injection), $0.5 \mathrm{mg} / \mathrm{kg}$ MDPV (120-180 min after injection), and $1.0 \mathrm{mg} / \mathrm{kg} \mathrm{MDPV}$ (120-150 min after injection).

The results for the vapor-inhalation conditions (PG, MA, MDPV) in this experiment were next compared with the saline and $1.0 \mathrm{mg} / \mathrm{kg}$ MA and MDPV, i.p. dose conditions in a single analysis. The ANOVA confirmed that there was a significant effect of Time $(\mathrm{F}(7,84)=33.38 ; P<0.0001)$ and Dose Condition $(\mathrm{F}(5,60)=10.17 ; P<0.0001)$ and of the
Time $\times$ Dose Condition interaction $(\mathrm{F}(35,420)=3.01$; $P<0.0001)$ on activity rate. Tukey's post hoc test confirmed first that activity levels were higher than their respective vehicle controls after $1.0 \mathrm{mg} / \mathrm{kg}$ MA i.p. (90-150 min after injection), $1.0 \mathrm{mg} / \mathrm{kg}$ MDPV i.p. (90 min after injection), MA vapor (60-120 min after initiation), and MDPV vapor (60-90 min after initiation) administration. The post hoc test further confirmed that MA vapor exposure significantly increased activity relative to i.p. administration of $1.0 \mathrm{mg} / \mathrm{kg}$ MA (60 min after injection/vapor initiation) and $1.0 \mathrm{mg} / \mathrm{kg}$ MDPV $(60,120 \mathrm{~min})$ as well as relative to MDPV vapor (120 min). Activity was higher after $1.0 \mathrm{mg} / \mathrm{kg}$ MA i.p. compared with MDPV vapor $150 \mathrm{~min}$ after injection/vapor initiation.

The ANOVA comparing body temperature responses to the second round of vapor with the corresponding $1.0 \mathrm{mg} / \mathrm{kg} \mathrm{MA}$ and MDPV i.p. challenge conditions confirmed that there was a significant effect of Time $(F(7,84)=28.30 ; P<0.0001)$ and Dose Condition $(\mathrm{F}(5,60)=7.33 ; P<0.0001)$ and of the Time $\times$ Dose Condition interaction $(\mathrm{F}(35,420)=2.26 ; \mathrm{P}<0.0001)$. Tukey's post hoc test further confirmed that significantly higher body temperature was observed after MA vapor inhalation compared with MA $1.0 \mathrm{mg} / \mathrm{kg}$ i.p. (60-180 min time point) and temperature was higher after MDPV vapor compared with MDPV $1.0 \mathrm{mg} / \mathrm{kg}$ i.p. (60 min time point). A significantly higher body temperature was confirmed for MDPV $1.0 \mathrm{mg} / \mathrm{kg}$, i.p. (150 min time point) versus vehicle i.p., but no other differences between drug and the respective vehicle conditions were confirmed. 
Table 2 Body Temperature Responses to Intraperitoneal Stimulants

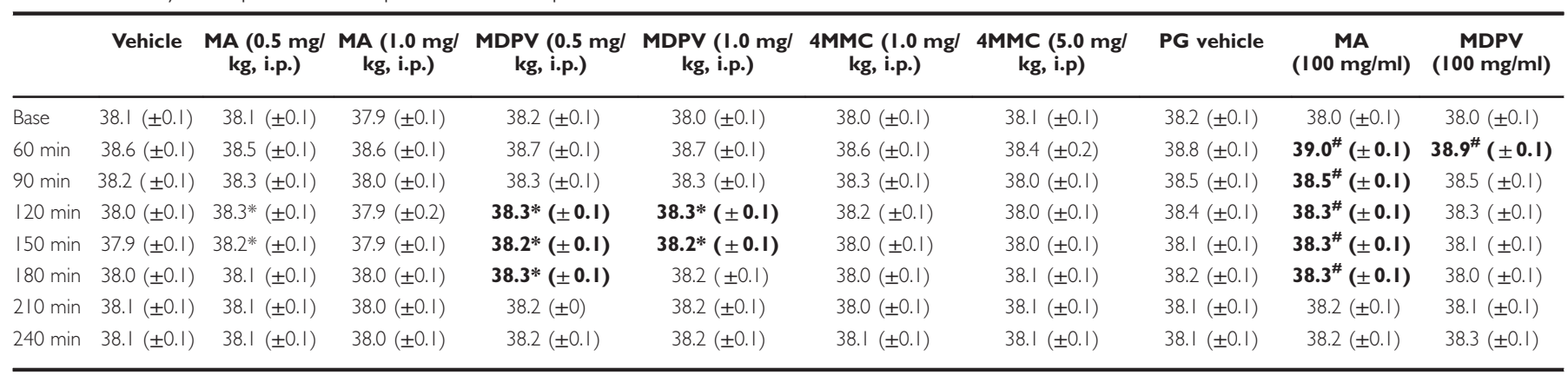

Abbreviations: MA, methamphetamine; MDPV, 3,4-methylenedioxypyrovalerone; 4MMC, 4-methylmethcathinone; PG, propylene glycol vehicle.

Mean $(N=13$; SEM) body temperature observed for baseline and then in the intervals following i.p. injection or vapor initiation. Significant differences from the PG vehicle condition at a given time point are indicated by the symbol * and differences between vapor exposure and the $1.0 \mathrm{mg} / \mathrm{kg}$ i.p. condition for MA and MDPV, respectively, are indicated by the symbol \# and are in bold.

a

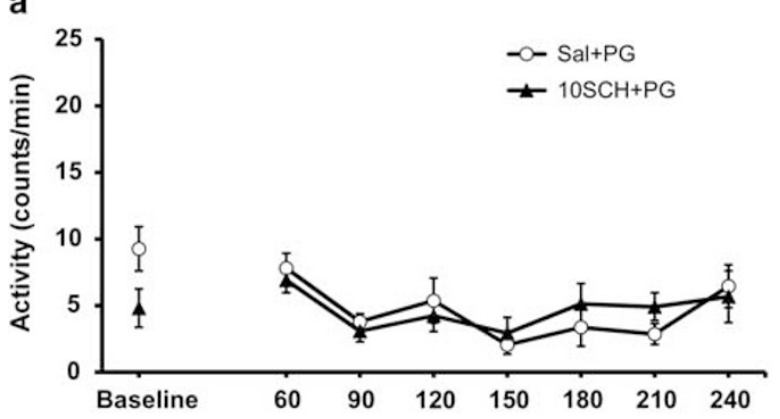

C

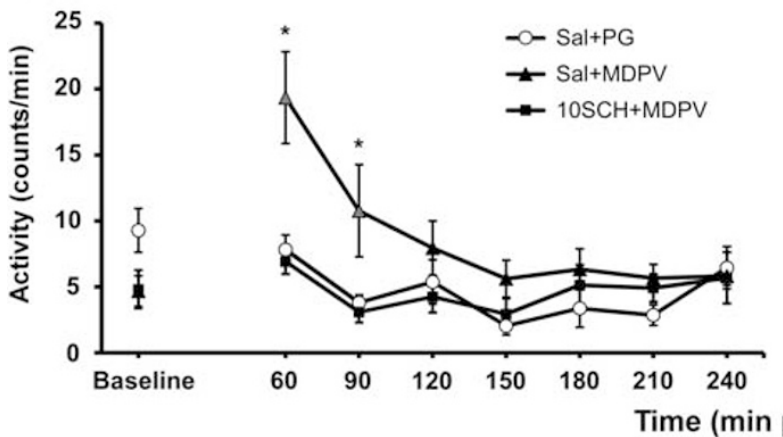

b

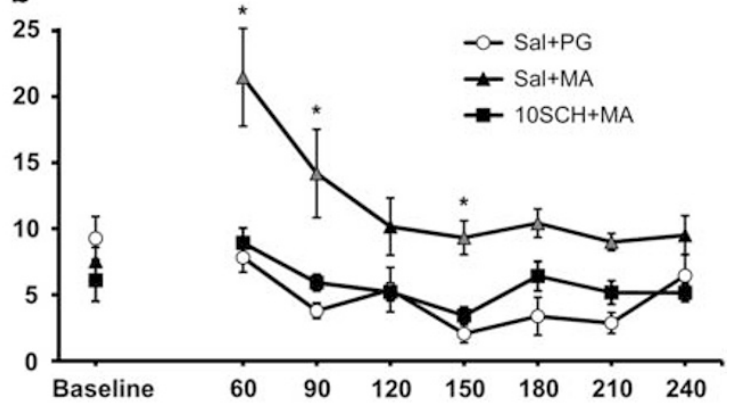

d

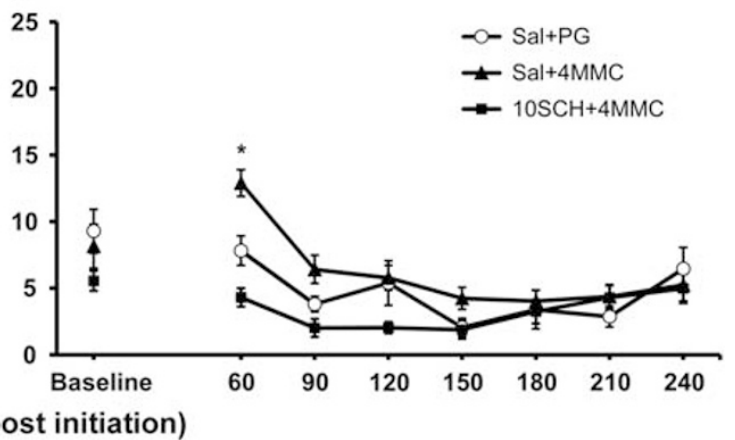

Figure 3 Mean $(\mathrm{N}=7 ; \pm \mathrm{SEM})$ activity rates after inhalation of (a) PG, (b) methamphetamine (MA; $100 \mathrm{mg} / \mathrm{ml})$, (c) MDPV, or (d) mephedrone/4MMC vapor following pretreatment with saline (Sal) or SCH23390 (I 0 gg/kg, i.p.; $10 \mathrm{SCH})$. Gray shaded symbols indicate a significant difference from PG vehicle at the corresponding time point and the symbol * indicates difference from corresponding SCH23390 pretreatment condition. The saline+PG control data are included in every panel for comparison.

\section{Experiment 3: D1 Receptor Antagonism of Locomotor Response to Vapor Methamphetamine}

The mean locomotor response to MA vapor inhalation was attenuated by pretreatment with the dopamine subtype-1 (D1) receptor antagonist SCH23390 (Figure 3). A naive group of male Wistar rats $(N=7)$ received 30 min exposure to PG, MDPV $(100 \mathrm{mg} / \mathrm{ml})$, and mephedrone $(200 \mathrm{mg} / \mathrm{ml})$ in randomized order with either saline or $10 \mu \mathrm{g} \mathrm{SCH} 23390$, i.p. administered before the session; this was followed with a $30 \mathrm{~min}$ exposure to MA $(100 \mathrm{mg} / \mathrm{ml})$ with saline or $10 \mu \mathrm{g}$ SCH23390, i.p. administered before the session in a balanced order. The ANOVA including all eight treatment conditions confirmed a significant effect of Time $(\mathrm{F}(7,42)=17.32$; $P<0.0001)$, of Drug Treatment Condition $(\mathrm{F}(7,42)=13.22$; $P<0.0001)$, and of the Time $\times$ Drug Treatment Condition interaction $(\mathrm{F}(49,294)=3.12 ; P<0.0001)$ on activity. Tukey's post hoc test confirmed that activity was higher when saline was injected before MDPV (60-90 min after vapor initiation), mephedrone (60 min), or MA (60-90, $150 \mathrm{~min})$ compared with the respective $10 \mu \mathrm{g} \mathrm{SCH} 23390$ pretreatment. Activity was also higher compared with the Sal+PG condition after MDPV (60-90 min after vapor initiation) or MA (60-90, 150-210 min) inhalation. Finally, activity was lower in the Sal+4MMC condition compared with the 

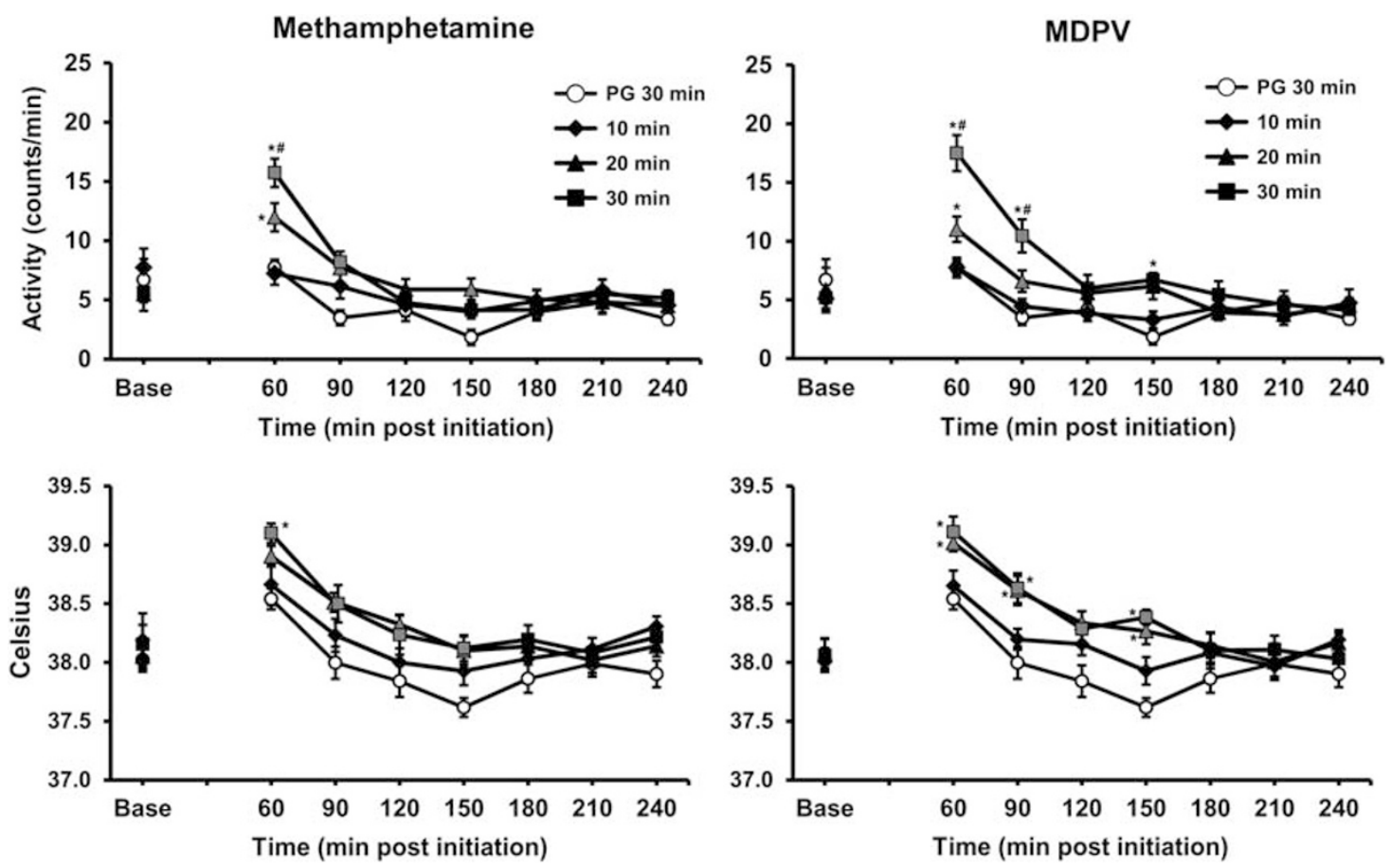

Figure 4 Mean ( $N=7 ; \pm$ SEM) activity rates (upper panels) and body temperature (lower panels) after inhalation of methamphetamine (left panels) or MDPV (right panels) for 10,20, or $30 \mathrm{~min}$. The drug concentration was $12.5 \mathrm{mg} / \mathrm{ml}$ and the PG vehicle condition was for 30 min (the single PG challenge is repeated in MA and MDPV panels). Significant differences from the PG condition are indicated with gray shaded symbols, from the 10 min condition by the symbol * and between the 20 and 30 min conditions by the symbol \# Base = preinhalation baseline.

Sal+MA (60-90, 180 min after vapor initiation) and Sal+MDPV (60 min) conditions.

The subsequent time-course studies in this group confirmed dose-dependent effects of drug inhalation on locomotor activity (Figure 4). MA inhalation dosedependently altered activity and the ANOVA confirmed significant effects of Time after inhalation $(F(7,42)=24.93$; $P<0.0001)$, of Drug Treatment Condition $(\mathrm{F}(3,18)=8.57$; $P<0.001)$, and of the Time $\times$ Drug Treatment Condition interaction $(\mathrm{F}(21,126)=4.31 ; P<0.0001)$ on activity rate. Tukey's post hoc test confirmed that activity differed across all three MA inhalation durations at $60 \mathrm{~min}$ after the initiation and relative to vehicle after $20 \mathrm{~min}$ (60-90, $150 \mathrm{~min}$ after initiation) or $30 \mathrm{~min}$ (60-90 min after initiation) of MA. Body temperature after MA inhalation was significantly altered by Time after initiation $(F(7,42)=19.65$; $P<0.0001)$ and Drug Treatment Condition $(\mathrm{F}(3,18)=6.31$; $P<0.005)$ but not by the interaction of factors. Tukey's post hoc test confirmed that body temperature was higher after 20 or $30 \mathrm{~min}$ of MA inhalation compared with the PG (60-150 min after initiation) and higher after $30 \mathrm{~min}$ of MA inhalation compared with $10 \mathrm{~min}$ (60 min after initiation).

The ANOVA of the MDPV conditions confirmed significant effects of Time after initiation $(\mathrm{F}(7,42)=45.66$; $P<0.0001)$, of Drug Treatment Condition $(\mathrm{F}(2,12)=9.23$; $P<0.005)$, and of the interaction $(\mathrm{F}(14,84)=4.93 ; P<0.0001)$ on activity rate. Tukey's post hoc test confirmed that activity differed across all three inhalation durations at $60 \mathrm{~min}$ after the initiation of inhalation, the $30 \mathrm{~min}$ duration resulted in higher activity than 10 or $20 \mathrm{~min}$ exposure at $90 \mathrm{~min}$ and $10 \mathrm{~min}$ inhalation significantly less activity $150 \mathrm{~min}$ after initiation. Body temperature after MDPV inhalation was significantly altered by Time after initiation $(\mathrm{F}(7,42)=25.40$; $P<0.0001)$, by Drug Treatment Condition $(\mathrm{F}(3,18)=6.16$; $P<0.005)$, and by the interaction $(\mathrm{F}(21,126)=2.55 ; P<0.001)$. Tukey's post hoc test confirmed that body temperature was higher after 30 or 20 min of inhalation compared with PG (60-150 min after-initiation) as well as the $10 \mathrm{~min}$ condition (60-90, $150 \mathrm{~min})$.

\section{Experiment 4: Effect of Vapor MA and MDPV Administration on Wheel Activity}

The wheel quarter rotations following MA and MDPV vapor inhalation ( $40 \mathrm{~min}$ ) were summed across $30 \mathrm{~min}$ intervals for analysis. For lower dose conditions of MA and MDPV $(25 \mathrm{mg} / \mathrm{ml})$ (Figure 5a), the ANOVA confirmed a significant effect of Time $(\mathrm{F}(3,21)=6.385 ; P<0.01)$. Wheel activity was significantly higher in the first $30 \mathrm{~min}$ bin compared with all subsequent bins following PG exposure and the $120 \mathrm{~min}$ interval following MA vapor inhalation. For higher dose conditions of MA and MDPV (100 mg/ml) (Figure 5b), the ANOVA confirmed a significant effect of Vaporized Drug Treatment Condition $(\mathrm{F}(2,14)=5.614 ; P<0.05)$ and of the Time $\times$ Vaporized Drug Treatment Condition interaction $(\mathrm{F}(6,42)=8.234 ; P<0.0001)$. Tukey's post hoc test confirmed that MA vapor inhalation resulted in significantly decreased activity relative to the $P G$ inhalation in the first $30 \mathrm{~min}$, and MDPV vapor inhalation resulted in significantly decreased activity relative to the PG in the first $30 \mathrm{~min}$ and increased activity in the $60-90 \mathrm{~min}$ intervals. Activity following MA and MDPV vapor inhalation was significantly different at $60 \mathrm{~min}$. Wheel activity was significantly higher in the first 


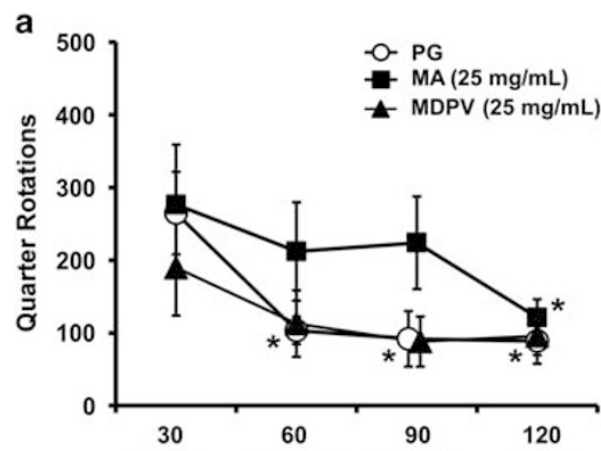

Minutes After Inhalation Termination
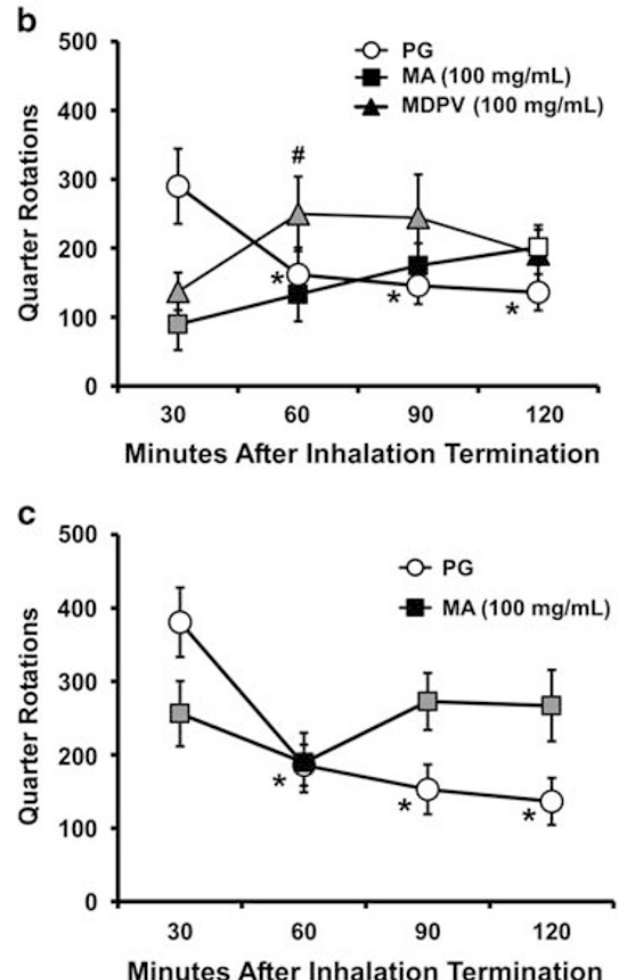

Figure 5 Mean $(N=7 ; \pm S E M)$ wheel activity for male Wistar rats after inhalation of (a) the propylene glycol (PG) vehicle, methamphetamine (MA; $25 \mathrm{mg} / \mathrm{ml}$ in PG), or MDPV (25 mg/ml in PG) and (b) methamphetamine (MA; $100 \mathrm{mg} / \mathrm{ml}$ in PG), MDPV $(100 \mathrm{mg} / \mathrm{ml}$ in PG), or the vehicle for 40 min. (c) Mean ( $N=16$; \pm SEM) wheel activity for another group of male Wistar rats after inhalation of MA $(100 \mathrm{mg} / \mathrm{ml}$ in PG vehicle) or the vehicle for $20 \mathrm{~min}$. Gray shaded symbols indicate a significant difference from PG. A significant difference from the $30 \mathrm{~min}$ time point within an inhalation condition is indicated with the symbol * and a difference from MA with the symbol \# for corresponding time points.

30 min bin compared with all subsequent bins following PG exposure.

A final study was conducted to test $20 \mathrm{~min}$ inhalation of MA at the higher $(100 \mathrm{mg} / \mathrm{ml})$ concentration (Figure $5 \mathrm{c}$ ). The ANOVA confirmed a significant effect of Time $(\mathrm{F}(3,45)=9.23 ; P<0.0001)$ and of the Vaporized Drug Treatment Condition $\times$ Time interaction $(\mathrm{F}(3,45)=12.08$; $P<0.0001)$ on wheel activity. Sidak's post hoc test confirmed that MA vapor inhalation resulted in significantly reduced activity relative to the PG inhalation in the first $30 \mathrm{~min}$ and increased activity in the 90-120 min intervals. In addition,
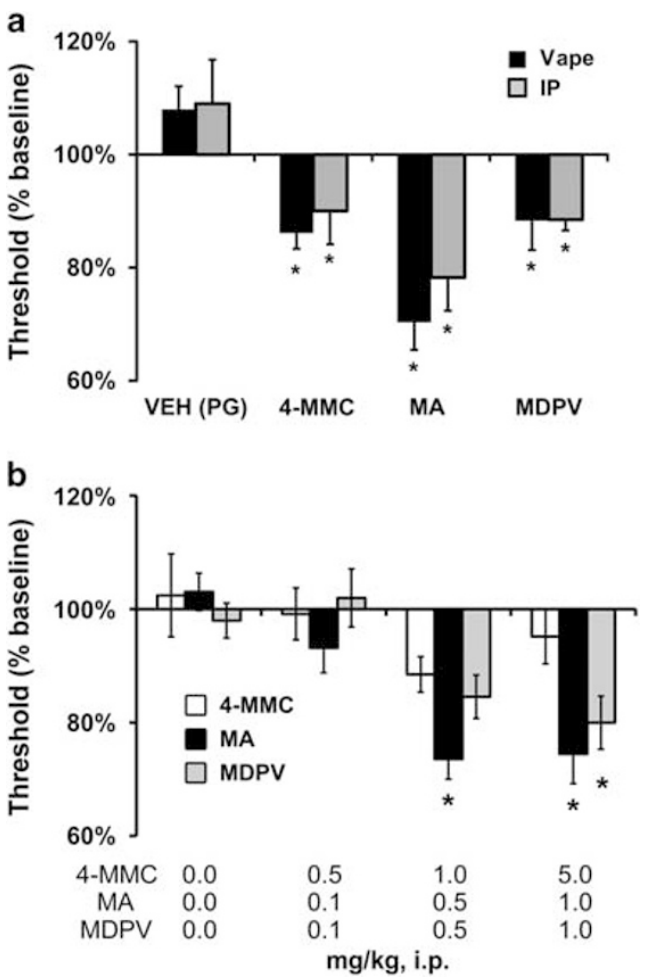

Figure 6 Inhaled and i.p. exposure to mephedrone (4MMC; $200 \mathrm{mg} / \mathrm{ml}$ in PG), methamphetamine (MA; $100 \mathrm{mg} / \mathrm{ml})$, and 3,4-methylenedioxypyrovalerone (MDPV; $100 \mathrm{mg} / \mathrm{ml}$ ) decreases threshold of intracranial selfstimulation (ICSS) reward. (a) Mean $(N=9-10 ; \pm$ SEM) change in ICSS threshold produced by i.p. administration of saline, $4 M M C(1.0 \mathrm{mg} / \mathrm{kg})$. MA $(0.5 \mathrm{mg} / \mathrm{kg})$, or MDPV $(0.5 \mathrm{mg} / \mathrm{kg})$ is compared with the average of the two exposures to inhaled PG, 4MMC, MA, or MDPV. (b) Mean ( $N=10$; \pm SEM) change in ICSS threshold produced by i.p. administration of three doses of 4MMC, MA, and MDPV. In all panels, significant differences from the respective vehicle condition is indicated by the symbol.

wheel activity was significantly higher in the first $30 \mathrm{~min}$ bin compared with all subsequent bins following PG exposure but no differences were confirmed across time within the MA vapor condition.

\section{Experiment 5: Effect of Vapor and Intraperitoneal Administration on ICSS Threshold}

The average threshold obtained across the two inhalation exposures for MA, MDPV, and mephedrone (Figure 6a) was compared with thresholds obtained after i.p. injection (15 min before session start) of mephedrone $(1.0 \mathrm{mg} / \mathrm{kg})$, MA $(0.5 \mathrm{mg} / \mathrm{kg})$, or MDPV $(0.5 \mathrm{mg} / \mathrm{kg})$. The ANOVA confirmed that there was a significant effect of the Drug Condition $(\mathrm{F}(3,51)=16.60 ; P<0.0001)$, but not of Route or of the Drug Condition $\times$ Route interaction, on ICSS thresholds. The post hoc test (Dunnett) confirmed that ICSS thresholds following mephedrone or MA vapor inhalation were significantly lower than those obtained after the PG vehicle condition and thresholds after MDPV or MA i.p. differed significantly from saline i.p.

Follow-up studies were conducted to test three doses each of mephedrone $(0.0,0.5,1.0$, and $5.0 \mathrm{mg} / \mathrm{kg}$, i.p.), MDPV $(0.0,0.1,0.5$, and $1.0 \mathrm{mg} / \mathrm{kg}$, i.p.), or MA $(0.0,0.1,0.5$, and $1.0 \mathrm{mg} / \mathrm{kg}$, i.p.) to determine whether appropriate doses had 
been selected for the i.p./Vapor comparison above (Figure 6b). Doses of the three drugs were estimated as roughly comparable as Low, Medium, and High based on prior locomotor studies and were thus analyzed in these categories. The ANOVA confirmed a significant effect of the Drug $(\mathrm{F}(2,18)=7.61 ; P<0.005)$ and of Dose $(\mathrm{F}(3,27)=18.09 ; P<0.0001)$ but not of the interaction. Dunnett's post hoc test confirmed that reward thresholds were significantly lower than the respective vehicle condition after $1.0 \mathrm{mg} / \mathrm{kg}$ MDPV i.p. and after 0.5 or $1.0 \mathrm{mg} / \mathrm{kg}$ MA i.p. The only significant difference confirmed across drugs at a given dose rank was between the high doses of MA and mephedrone. No lasting effects of drug days on ICSS thresholds obtained on following (nontreatment) days were confirmed in this study.

\section{DISCUSSION}

This study has, for the first time, described a reliable technique for the delivery of psychomotor stimulant drugs to unrestrained rats via e-cigarette based ('vape') technology and a PG vehicle that gives excellent congruency with growing trends among human users. Vaporized delivery of MA, MDPV, and mephedrone (4MMC) significantly increased locomotor activity within a housing chamber and decreased the ICSS reward threshold of rats. Body temperature was elevated by inhaled MA and MDPV and wheel activity was also altered. The magnitude of effects depended on the duration of inhalation exposure and/or the concentration in the PG, thereby confirming a dose-dependent relationship. Thus, this method proved effective for three different stimulants and the comparison of the behavioral effects of vapor exposure with i.p. administration confirmed an approximate similarity to the effects of $1.0-5.0 \mathrm{mg} / \mathrm{kg}$ mephedrone i.p. or $0.5-1.0 \mathrm{mg} / \mathrm{kg} \mathrm{MA}$ and MDPV i.p.

Although the synthetic cathinone compounds MDPV and mephedrone are less well studied than MA, these compounds can stimulate motor activity in mice (Fantegrossi et al, 2013; Fuwa et al, 2009; Gatch et al, 2013) and rats (Aarde et al, 2013b; Baumann et al, 2012, 2013; Huang et al, 2012; Wright et al, 2012) when administered by injection. MDPV appears to be approximately as potent as MA whereas mephedrone is less potent in most prior studies, and thus the relative potencies identified for vapor inhalation in this study (a threshold for effects at $12.5-25 \mathrm{mg} / \mathrm{ml}$ for MA and MDPV vs above $100 \mathrm{mg} / \mathrm{ml}$ for mephedrone, and significant differences in experiment 3 between mephedrone and the other two drugs) are roughly consistent with prior results using other routes of administration. The attenuation of locomotor response by SCH23390 confirms the mechanistic involvement of D1-like receptors. SCH23390 has been previously shown to block expression of MA-, mephedrone-, and cocaine-induced hyperactivity in rodents after injection (Hall et al, 2009; Lisek et al, 2012; Rauhut, 2015; Schindler and Carmona, 2002), and MDPV-induced hyperactivity has also been shown to be mediated through a dopamine receptordependent mechanism (Marusich et al, 2014; Novellas et al, 2015). Our findings demonstrate that an increase in locomotor activity induced by the inhalation of MA, MDPV, and mephedrone is similarly mediated by a D1-like receptordependent mechanism.
The wheel activity data provide both converging confirmation of the telemetry measure of stimulation and a conceptual link to the inverted $U$ dose-response functions often observed with large dose ranges of injected psychostimulants. Inhalation of MA (Figure 5c) and MDPV (Figure 5b) at sufficiently high dose conditions resulted in an initial suppression of wheel activity followed by a sustained increase in activity. Similarly, although the injection of a peak stimulant dose of MA, MDPV, or $\alpha$-PVP results in immediate locomotor increases followed by a monotonic decay (Aarde et al, 2015a; Miller et al, 2013b), higher doses induce activity suppression (or lack of elevation) followed by an activity rebound later in the session as plasma levels decline. This is highly congruent with the seminal work by Segal, Kuczenski, and colleagues (Cho et al, 1999; Conti et al, 1997; Kuczenski et al, 1997) that shows a shift to alternate behaviors (ie, patterns of stereotyped repetitive activity) instead of locomotion. This well-established pattern of initial suppression followed by an activity rebound was not observed in any of the inhalation telemetry activity data in this study and our new lowerexposure conditions reinforce the inference that these data are on the ascending/peak part of the curve. The wheel activity data are, however, consistent with the initial suppression/later rebound pattern. The reason is conceptually similar to locomotion/stereotypy relationships, that is some other behavior is taking place instead of wheel running. In this case, however, the alternate behavior is increased home chamber activity (as per the radiotelemetry results) rather than focal stereotypy.

This study also found that inhalation of these three stimulants reduced ICSS thresholds with the magnitude of reduction equivalent to the effects produced by injection of the same drugs. Acute administration of psychomotor stimulants such as methamphetamine, MDPV, and mephedrone via i.p. injection has been shown to lower ICSS thresholds in rodents (Bauer et al, 2013; Bonano et al, 2014; Harris et al, 2015; Robinson et al, 2012; Watterson et al, 2014). The relative potencies determined by locomotor stimulant effects in this study and our prior work (Aarde et al, 2013a, b; Huang et al, 2012; Wright et al, 2012) were effective in selecting appropriate doses to alter ICSS thresholds. Thus, the efficacy of this method for the delivery of relevant doses of psychomotor stimulants for behavioral end points that are more closely related to addictive liability was also demonstrated.

The first experiment identified a threshold for effective dosing with mephedrone between the 100 and $200 \mathrm{mg} / \mathrm{ml}$ concentrations. In contrast, MA and MDPV produced approximately equivalent effects when $25 v s 100 \mathrm{mg} / \mathrm{ml}$ was delivered over $40 \mathrm{~min}$, and thus differences in drug concentration in the vapor were not functionally different for these compounds under these conditions. The study that compared 10-30 min of exposure to MA or MDPV at a lower $(12.5 \mathrm{mg} / \mathrm{ml})$ concentration, however, illustrated clear inhalation time-dependent effects, thereby showing that this method can vary the drug dose. Similarly, conditions that did not change locomotion (not shown) were identified for MDPV (25 mg/ml, one puff per $5 \mathrm{~min}$ for $40 \mathrm{~min}$ ), for cocaine $(200 \mathrm{mg} / \mathrm{ml} ; 4$ puffs per $5 \mathrm{~min}$ over $40 \mathrm{~min})$, and for methylone $(100 \mathrm{mg} / \mathrm{ml}$; 4 puffs per $5 \mathrm{~min}$ over $40 \mathrm{~min})$. This is roughly consistent with the relative potency of these drugs 
under i.p. or s.c. injection, see (Aarde et al, 2013b, 2015b; Miller et al, 2013a; Wright et al, 2012) and the i.p. challenges conducted in this study.

As a minor caveat, this was mostly a within-group study and the treatment order for the various challenges was not completely randomized. Nevertheless, the results were for the most part quite orderly and consistent and the locomotor effects were replicated across two cohorts of subjects for both telemetry and wheel assays. There was a moderate attenuation of the locomotor effect of drug across the first experiment, as shown in the direct before/after comparison of the effects of $100 \mathrm{mg} / \mathrm{ml} \mathrm{MA}$ or MDPV (Figures $1 \mathrm{~b}$ and $\mathrm{c}$ $v s$ Figure $2 \mathrm{~d}$ ), providing an estimate of the likely magnitude and direction of plasticity (ie, tolerance) that might be observed with intermittent challenges with a variety of psychostimulant drugs as outlined for experiment 1 . There was no change in the activity observed following PG/veh across a similar interval of time, and thus this is not because of a generalized reduction in locomotion and suggests some degree of tolerance to the effect of stimulant drugs. This analysis also shows that the interpretation of the original MA/MDPV effects on activity (ie, similar in magnitude, MA effects lasting longer) is not compromised by the original treatment order. Similarly, this repetition shows that the higher concentration needed to produce locomotor effects of mephedrone was not a result of tolerance as both MA and MDPV were effective at the $100 \mathrm{mg} / \mathrm{ml}$ concentration before and after the mephedrone study. Finally, dosing conditions were not adjusted by body weight that may have introduced a degree of variability in the drug exposure. This probably contributed less than changes, for example, in drug concentration or exposure duration, as the experiment 3 cohort was $\sim 79 \%$ of the weight of the experiment 1 cohort and the MA/MDPV/4MMC effects on activity were of comparable magnitude under similar concentration and exposure duration parameters. Additional investigation would be needed to fully determine tolerance and/or sensitization conditions with respect to dose, interexposure intervals, specific drug identity (MDPV, cocaine, and $\alpha$-PVP share a mechanism of action and thus might be expected to generate cross-tolerance) and rat strain, sex, or age.

It is also the case that this study could not evaluate all possible behavioral or physiological end points that might be of interest, given several decades worth of study of the effects of injected psychostimulant drugs in rats. Obvious next directions for this model include the effects of repeated closeinterval exposure to identify tolerance or sensitization, conditioned place-preference, self-administration, and an evaluation of blood levels, now that behaviorally relevant exposure ranges have been identified. It would also be of considerable interest to examine sex differences and developmental differences. Finally, this study featured involuntary drug exposure and it would be of significant interest to develop self-administration procedures. To this end we have presented preliminary vapor self-administration data at scientific meetings (Taffe et al, 2015b).

In conclusion, inhalation of methamphetamine, MDPV, and mephedrone produces locomotor stimulant effects and a reduction of ICSS thresholds in rats. Therefore, this study demonstrates the efficacy of delivering behaviorally relevant doses of three different stimulant drugs to rats via inhalation. As this was accomplished using e-cigarette-type technology, and one of the most commonly used e-cigarette vehicles, this method has great translational relevance. This complements a recent demonstration that this inhalation approach produces hypothermic, hypolocomotor, and antinociceptive effects of $\Delta^{9}$-tetrahydrocannabinol in rats (Nguyen et al, 2016). This method will be increasingly important as the availability of e-cigarette vaping devices grows and the use for delivery of psychoactive drugs other than nicotine expands.

\section{FUNDING AND DISCLOSURE}

Development of the apparatus was supported by La Jolla Alcohol Research, and MC is inventor on a patent for this device. SAV consults for La Jolla Alcohol Research. The remaining authors declare no conflicts of interest.

\section{ACKNOWLEDGMENTS}

This work was funded by support from the United States Public Health Service National Institutes of Health (R01DA024105, R01DA024705, R01DA035281, and R44DA041967) that had no direct input on the design, conduct, analysis, or publication of the findings. Subsets of these data were first presented at the Experimental Biology meeting in 2015 and the Annual Meeting of the Society for Neuroscience 2015. This is manuscript 29226 from The Scripps Research Institute.

\section{REFERENCES}

Aarde SM, Angrish D, Barlow DJ, Wright MJ Jr, Vandewater SA, Creehan KM et al (2013a). Mephedrone (4-methylmethcathinone) supports intravenous self-administration in SpragueDawley and Wistar rats. Addict Biol 18: 786-799.

Aarde SM, Creehan KM, Vandewater SA, Dickerson TJ, Taffe MA (2015a). In vivo potency and efficacy of the novel cathinone alpha-pyrrolidinopentiophenone and 3,4-methylenedioxypyrovalerone: self-administration and locomotor stimulation in male rats. Psychopharmacology 232: 3045-3055.

Aarde SM, Creehan KM, Vandewater SA, Dickerson TJ, Taffe MA (2015b). In vivo potency and efficacy of the novel cathinone $\alpha$-pyrrolidinopentiophenone and 3,4-methylenedioxypyrovalerone: Self-administration and locomotor stimulation in male rats. Psychopharmacology 232: 3045-3055.

Aarde SM, Huang PK, Creehan KM, Dickerson TJ, Taffe MA (2013b). The novel recreational drug 3,4-methylenedioxypyrovalerone (MDPV) is a potent psychomotor stimulant: self-administration and locomotor activity in rats. Neuropharmacology 71: $130-140$

Aarde SM, Miller ML, Creehan KM, Vandewater SA, Taffe MA (2015c). One day access to a running wheel reduces selfadministration of d-methamphetamine, MDMA and methylone. Drug Alcohol Depend 151: 151-158.

Anderson C (2015). Flakka, Synthetic Drug Behind Increasingly Bizarre Crimes Associated Press. The Associated Press: New York, NY.

Bauer CT, Banks ML, Blough BE, Negus SS (2013). Use of intracranial self-stimulation to evaluate abuse-related and abuselimiting effects of monoamine releasers in rats. $\mathrm{Br} J$ Pharmacol 168: 850-862.

Baumann MH, Ayestas MA Jr, Partilla JS, Sink JR, Shulgin AT, Daley PF et al (2012). The designer methcathinone analogs, mephedrone and methylone, are substrates for monoamine 
transporters in brain tissue. Neuropsychopharmacology 37: 1192-1203.

Baumann MH, Partilla JS, Lehner KR, Thorndike EB, Hoffman AF, Holy $M$ et al (2013). Powerful cocaine-like actions of 3,4-Methylenedioxypyrovalerone (MDPV), a principal constituent of psychoactive 'bath salts' products. Neuropsychopharmacology 38: 552-562.

Bonano JS, Glennon RA, De Felice LJ, Banks ML, Negus SS (2014). Abuse-related and abuse-limiting effects of methcathinone and the synthetic "bath salts" cathinone analogs methylenedioxypyrovalerone (MDPV), methylone and mephedrone on intracranial self-stimulation in rats. Psychopharmacology 231: 199-207.

Cho AK, Melega WP, Kuczenski R, Segal DS, Schmitz DA (1999). Caudate-putamen dopamine and stereotypy response profiles after intravenous and subcutaneous amphetamine. Synapse 31: 125-133.

Comer SD, Hunt VR, Carroll ME (1994). Effects of concurrent saccharin availability and buprenorphine pretreatment on demand for smoked cocaine base in rhesus monkeys. Psychopharmacology 115: 15-23.

Comer SD, Turner DM, Carroll ME (1995). Effects of food deprivation on cocaine base smoking in rhesus monkeys. Psychopharmacology 119: 127-132.

Conti LH, Segal DS, Kuczenski R (1997). Maintenance of amphetamine-induced stereotypy and locomotion requires ongoing dopamine receptor activation. Psychopharmacology 130: 183-188.

Das-Douglas M, Colfax G, Moss AR, Bangsberg DR, Hahn JA (2008). Tripling of methamphetamine/amphetamine use among homeless and marginally housed persons, 1996-2003. J Urban Health 85: 239-249.

Evans D (2014). Men Arrested for Using E-Cigarette to Smoke Meth Foxatlanta. FoxAtlanta.com: Atlanta, GA.

Fantegrossi WE, Gannon BM, Zimmerman SM, Rice KC (2013). In vivo effects of abused 'bath salt' constituent 3,4-methylenedioxypyrovalerone (MDPV) in mice: drug discrimination, thermoregulation, and locomotor activity. Neuropsychopharmacology 38: $563-573$.

Fuwa T, Kodama T, Honda Y, Tanaka T, Kubo Y, Ohashi N et al (2009). Influence of methylenedioxypyrovalerone on central nervous system using microdialysis method. ChemoBio Int Manag 5: 62-72.

Gatch MB, Taylor CM, Forster MJ (2013). Locomotor stimulant and discriminative stimulus effects of 'bath salt' cathinones. Behav Pharmacol 24: 437-447.

George O, Grieder TE, Cole M, Koob GF (2010). Exposure to chronic intermittent nicotine vapor induces nicotine dependence. Pharmacol Biochem Behav 96: 104-107.

Hall DA, Powers JP, Gulley JM (2009). Blockade of D1 dopamine receptors in the medial prefrontal cortex attenuates amphetamine- and methamphetamine-induced locomotor activity in the rat. Brain Res 1300: 51-57.

Harris AC, LeSage MG, Shelley D, Perry JL, Pentel PR, Owens SM (2015). The anti-(+)-methamphetamine monoclonal antibody mAb7F9 attenuates acute (+)-methamphetamine effects on intracranial self-stimulation in rats. PLoS One 10: e0118787.

Heinzerling KG, Swanson AN, Kim S, Cederblom L, Moe A, Ling W et al (2010). Randomized, double-blind, placebo-controlled trial of modafinil for the treatment of methamphetamine dependence. Drug Alcohol Depend 109: 20-29.

Huang PK, Aarde SM, Angrish D, Houseknecht KL, Dickerson TJ, Taffe MA (2012). Contrasting effects of d-methamphetamine, 3,4-methylenedioxymethamphetamine, 3,4-methylenedioxypyrovalerone, and 4-methylmethcathinone on wheel activity in rats. Drug Alcohol Depend 126: 168-175.

Hueza IM, Ponce F, Garcia RC, Marcourakis T, Yonamine M, Mantovani Cde C et al (2016). A new exposure model to evaluate smoked illicit drugs in rodents: a study of crack cocaine. J Pharmacol Toxicol Methods 77: 17-23.
Johnson PS, Johnson MW (2014). Investigation of "bath salts" use patterns within an online sample of users in the United States. J Psychoactive Drugs 46: 369-378.

Kenny PJ, Markou A (2006). Nicotine self-administration acutely activates brain reward systems and induces a longlasting increase in reward sensitivity. Neuropsychopharmacology 31: 1203-1211.

Kornetsky C, Esposito RU (1979). Euphorigenic drugs: effects on the reward pathways of the brain. Fed Proc 38: 2473-2476.

Kuczenski R, Segal DS, Todd PK (1997). Behavioral sensitization and extracellular dopamine responses to amphetamine after various treatments. Psychopharmacology 134: 221-229.

Lichtman AH, Sathe P, Dimen KR, Martin BR (1995). Acute tolerance to the cardiovascular effects of volatilized cocaine free base in rats. Drug Alcohol Depend 38: 247-254.

Lisek R, Xu W, Yuvasheva E, Chiu YT, Reitz AB, Liu-Chen LY et al (2012). Mephedrone ('bath salt') elicits conditioned place preference and dopamine-sensitive motor activation. Drug and alcohol dependence 126: 257-262.

Markou A, Koob GF (1992). Construct validity of a self-stimulation threshold paradigm: effects of reward and performance manipulations. Physiol Behav 51: 111-119.

Marusich JA, Antonazzo KR, Wiley JL, Blough BE, Partilla JS, Baumann MH (2014). Pharmacology of novel synthetic stimulants structurally related to the "bath salts" constituent 3,4-methylenedioxypyrovalerone (MDPV). Neuropharmacology 87: 206-213.

Meng Y, Dukat M, Bridgen DT, Martin BR, Lichtman AH (1999). Pharmacological effects of methamphetamine and other stimulants via inhalation exposure. Drug Alcohol Depend 53: 111-120.

Miller ML, Creehan KM, Angrish D, Barlow DJ, Houseknecht KL, Dickerson TJ et al (2013a). Changes in ambient temperature differentially alter the thermoregulatory, cardiac and locomotor stimulant effects of 4-methylmethcathinone (mephedrone). Drug Alcohol Depend 127: 248-253.

Miller ML, Moreno AY, Aarde SM, Creehan KM, Vandewater SA, Vaillancourt BD et al (2013b). A methamphetamine vaccine attenuates methamphetamine-induced disruptions in thermoregulation and activity in rats. Biol Psychiatry 73: 721-728.

National Research Council (US) Committee for the Update of the Guide for the Care and Use of Laboratory Animals; Institute for Laboratory Animal Research (US) (2011). Guide for the Care and Use of Laboratory Animals: Eighth Edition. National Academies Press: Washington, DC. pp xxv 220 p. Available at http://www.ncbi.nlm.nih.gov/books/NBK54044/.

Newman JL, Carroll ME (2006). Reinforcing effects of smoked methamphetamine in rhesus monkeys. Psychopharmacology 188: 193-200.

Nguyen JD, Aarde SA, Vandewater SA, Grant Y, Stouffer DG, Parsons LH et al (2016). Inhaled delivery of $\Delta$ 9-tetrahydrocannabinol (THC) to rats by e-cigarette vapor technology. Neuropharmacology 109: 112-120.

Novellas J, Lopez-Arnau R, Carbo ML, Pubill D, Camarasa J, Escubedo E (2015). Concentrations of MDPV in rat striatum correlate with the psychostimulant effect. J Psychopharmacol 29: 1209-1218.

Rass O, Pacek LR, Johnson PS, Johnson MW (2015). Characterizing use patterns and perceptions of relative harm in dual users of electronic and tobacco cigarettes. Exp Clin Psychopharmacol 23: 494-503.

Rauhut AS (2015). Timing of SCH 23390 administration influences extinction of conditioned hyperactivity in mice. Behav Pharmacol 27: 73-76.

Robinson JE, Agoglia AE, Fish EW, Krouse MC, Malanga CJ (2012). Mephedrone (4-methylmethcathinone) and intracranial selfstimulation in C57BL/6J mice: comparison to cocaine. Behav Brain Res 234: 76-81. 
Schindler CW, Carmona GN (2002). Effects of dopamine agonists and antagonists on locomotor activity in male and female rats. Pharmacol Biochem Behav 72: 857-863.

Simmler L, Buser T, Donzelli M, Schramm Y, Dieu LH, Huwyler J et al (2013). Pharmacological characterization of designer cathinones in vitro. Br J Pharmacol 168 458-470.

Taffe MA, Creehan KM, Vandewater SA (2015a). Cannabidiol fails to reverse hypothermia or locomotor suppression induced by Delta -tetrahydrocannabinol in Sprague-Dawley rats. $\mathrm{Br} J$ Pharmacol 172 1783-1791.

Taffe MA, Nguyen JD, Vandewater SA, Grant Y, Cole M (2015b). Effects of Vaped Delivery of Psychomotor Stimulants to Rats. Society for Neuroscience Annual Meeting. Society for Neuroscience: Chicago, IL.
Watterson LR, Kufahl PR, Nemirovsky NE, Sewalia K, Grabenauer M, Thomas BF et al (2014). Potent rewarding and reinforcing effects of the synthetic cathinone 3,4-methylenedioxypyrovalerone (MDPV). Addict Biol 19: 165-174.

Wood E, Stoltz JA, Zhang R, Strathdee SA, Montaner JS, Kerr T (2008). Circumstances of first crystal methamphetamine use and initiation of injection drug use among high-risk youth. Drug Alcohol Rev 27: 270-276.

Wright MJ Jr, Angrish D, Aarde SM, Barlow DJ, Buczynski MW, Creehan KM et al (2012). Effect of ambient temperature on the thermoregulatory and locomotor stimulant effects of 4-methylmethcathinone in Wistar and Sprague-Dawley rats. PLoS One 7: e44652. 